\title{
Pharmacotoxicology of Non-fentanyl Derived New Synthetic Opioids
}

\author{
Renata Solimini ${ }^{1}$, Simona Pichini ${ }^{1 *}$, Roberta Pacifici ${ }^{1}$, Francesco P. Busardò ${ }^{2 \dagger}$ and \\ Raffaele Giorgetti ${ }^{3+}$ \\ ${ }^{1}$ National Centre on Addiction and Doping, Istituto Superiore di Sanità, Rome, Italy, ${ }^{2}$ Unit of Forensic Toxicology, \\ Department of Anatomical, Histological, Forensic and Orthopedic Sciences, Sapienza University of Rome, Rome, Italy, \\ ${ }^{3}$ Section of Legal Medicine, Università Politecnica delle Marche, Ancona, Italy
}

OPEN ACCESS

Edited by:

Francisco Lopez-Munoz, Universidad Camilo José Cela, Spain

Reviewed by:

Jason N. Peart

Griffith University, Australia

Eugene A. Kiyatkin,

National Institute on Drug Abuse

(NIDA), United States

${ }^{*}$ Correspondence:

Simona Pichini

simona.pichini@iss.it

tThese authors have contributed equally to this work.

Specialty section:

This article was submitted to

Neuropharmacology,

a section of the journal

Frontiers in Pharmacology

Received: 24 April 2018

Accepted: 31 May 2018

Published: 20 June 2018

Citation:

Solimini R, Pichini S, Pacifici R, Busardò FP and Giorgetti R (2018) Pharmacotoxicology of Non-fentanyl

Derived New Synthetic Opioids.

Front. Pharmacol. 9:654.

doi: 10.3389/fphar.2018.00654
A class of opioid agonists not structurally related to fentanyl, derived from research publications of pharmaceutical companies or patents within the United States and abroad are contributing to the current opioid epidemic. Novel synthetic opioids (NSOs) created to circumvent drug control laws such as U-47700, U-49900, AH-7921, or MT45 have no recognized therapeutic use, are clandestinely manufactured and sold on conventional or dark web. We herein provide a review of the pharmacological properties available on most of these substances trying to provide a better knowledge on these compounds, particularly with respect to toxicity and dangerous adverse effects in users. Indeed, these NSOs share not only a great potency of action and receptor affinity with respect to natural or synthetic opiates (e.g., morphine, heroin, and methadone) but also a non-negligible toxicity leading to intoxications and fatalities, posing a serious harm to public health and society.

Keywords: novel synthetic opioids, U-47700, U-49900, AH-7921, MT-45, toxicity, health threat

\section{INTRODUCTION}

Non-fentanyl derived novel synthetic opioids (NSOs) have initially emerged worldwide as nonillegal drugs diffused to replace heroin and thus circumvent prohibition laws, resulting in numerous abuse reports and overdose cases, especially across United States and Europe (Carroll et al., 2012; Armenian et al., 2017b; Baumann et al., 2017; Fabregat-Safont et al., 2017).

These NSOs are a broad family of analgesics and anesthetics, mainly synthesized in the 1970s, acting at the $\mathrm{mu}(\mu)$ opioid receptor, but also at the delta $(\delta)$ and kappa $(\kappa)$ ones. The power of physiological and psychological effects is different according to the specific synthetic opioid being used and the type of receptor that is activated or inhibited (Baumann et al., 2017; European Monitoring Centre for Drugs, and Drug Addiction [EMCDDA], 2017).

To precisely define this particular class of NSOs, it is worth mentioning that the alkaloid compounds naturally found in the opium poppy plant are defined opiates and include, among others, morphine, codeine, and thebaine as principal alkaloids.

Instead, substances such as hydromorphone, oxymorphone, and heroin are semisynthetic opioids made from morphine with pharmacological properties similar to those of opiates and affinity for one of the 7-transmembrane G protein-coupled opioid receptors (Raffa et al., 2018).

All the above reported opioids belong to the phenanthrene family, while the family of benzomorphans include, e.g., pentazocine phenazocine, dezocine, and eptazocine, developed through the modification of the basic phenanthrene structure of morphine (Cittern et al., 1986). Conversely, methadone is a phenylheptylamine agent whereas meperidine is a phenylpiperidine derivative (Knapp, 2002; Raffa et al., 2018). 
The family of phenylpiperidines (characterized by a phenyl moiety directly linked to a piperidine) includes also the NSO fentanyl (synthesized by P. Janssen in the 1960s) and its analogs, up to 1000 times more potent as analgesic than meperidine and differing in structure from the latter for a phenethyl group on the piperidine nitrogen in place of a methyl group (Elbaridi et al., 2017; Raffa et al., 2018).

While extensive literature has been published in regards to pharmacology and toxicology of fentanyl and its illicit analogs (Bäckberg et al., 2015; Mounteney et al., 2015; Dwyer et al., 2017; Giorgetti et al., 2017; Guerrieri et al., 2017; Helander et al., 2017a; Pichini et al., 2017a,b; Shoff et al., 2017; Suzuki and ElHaddad, 2017), the pharmacological and toxicological properties of non-fentanyl derived NSOs have not yet been reviewed in detail.

Compounds such as U-47700, U-51754, U-49900, U-448800, AH-7921 from the chemical family of benzamide, U-50488 and U-51754 from the acetamide family and MT-45 from the piperazine family are the NSOs most recently reported as health threats for opioids consumers (Mohr et al., 2016; Amin et al., 2017; Baumann et al., 2017; Domanski et al., 2017; FabregatSafont et al., 2017; Prekupec et al., 2017; Marchei et al., 2018). Indeed, this new generation of derivatives has been involved in a number of recent overdose deaths worldwide (Drug Enforcement Administration [DEA], 2016; Baumann et al., 2017; Domanski et al., 2017; Fabregat-Safont et al., 2017).

Clandestine manufacturing of NSOs has been pirated from scientific literature or patent filings published by pharmaceutical companies attempting to search for new therapeutic drugs without addiction-related adverse effects (Logan et al., 2017).

In a similar manner to fentanyl derivatives, these NSOs are being partly used as heroin adulterants or as constituents of counterfeit pain pills and they can be bought directly by users from online vendors via conventional web or cryptomarket (European Monitoring Centre for Drugs, and Drug Addiction [EMCDDA], 2016; Armenian et al., 2017b; Baumann et al., 2017; Van Hout and Hearne, 2017).

Similarly to morphine and heroin (opiates) or to semisynthetic opioids (like hydro- and oxycodone, hydro- and oxymorphone), these compounds produce CNS depressants effects such as respiratory depression, analgesia, hypothermia, sedation, euphoria, anxiety, sweating, disorientation, drowsiness, nausea, and miosis (Carroll et al., 2012; Guerrini et al., 2013; Hill and Thomas, 2016; Armenian et al., 2017b), and although the effects of tolerance and dependence may rapidly reach high levels, elevated risks of overdose and death are frequent for these compounds (United Nations Office on Drugs and Crime [UNODC], 2017b). Furthermore, the typical rewarding characteristics and the easy availability induce users to abuse of these opioids (Carroll et al., 2012).

The main NSOs AH-7921, MT-45, and U-47700 have been identified in Europe between 2013 and 2016, and over 40 deaths were reported to the European Monitoring Centre for Drugs and Drug Addiction in a short time after that AH-7921 and MT-45 were found out on the European drug market (EMCDDA) (European Monitoring Centre for Drugs, and Drug Addiction [EMCDDA], 2017). Moreover, in 2016 U-47700 has been the cause of at least 46 confirmed fatalities as well as the subject of 88 reports from forensic laboratories submissions in the United States (Fabregat-Safont et al., 2017).

Since the popularity of these substances is rapidly increasing and evolving over time, there is a great need to update all possible information, particularly with respect to their subjective and side effects and to tackle unsolved issues, including limited analytical methods to disclose and monitor different compounds (Katselou et al., 2015; Lucyk and Nelson, 2017).

To fill this gap, we here sought to report the latest information available on non-fentanyl derived NSOs U-47700, U-50488, U51754, U-49900, U-48800, AH-7921, and MT-45 with particular regard to their pharmacotoxicology and adverse effects on users (see Figure 1).

\section{Literature Search}

A literature search was performed on the multidisciplinary research databases Scopus and Web of Science and on PubMed for biomedical literature, to identify all the relevant articles (up to March 2018). The search terms used in different combinations were: new or novel synthetic opioid, designer opioid/drug, analgesics, narcotics, street drug, novel or new psychoactive substance/drug. Articles related to fentanyl and its derivatives were excluded. Further studies were retrieved by hand search through the reference lists of the selected articles. Moreover, a search for reports was conducted on Institutional websites, to identify documentation published by international agencies or institutions such as World Health Organization (WHO), United Nations Office on Drugs and Crime (UNODC), United States Drug Enforcement Administration (DEA), and European Monitoring Centre for Drugs and Drug Addiction (EMCDDA). Only articles or reports written in English were selected. All articles were screened independently by three of the authors to determine their relevance in the framework of the current review and only those selected at least by two of them were included.

\section{NSOs of Benzamide Family U-47700 and U-48800}

U-47700 (3,4-dichloro- $N$-[(1R,2R)-2-(dimethylamino) cyclohexyl]- $N$-methylbenzamide), also known under the street names of Pinky (because impurities in its synthesis cause the drug powder to be slightly pink in color), U4 or Fake morphine, is an example of a non-fentanyl benzamide compound initially individuated as a heroin adulterant and as constituent of counterfeit analgesic pills, mimicking pharmaceutical opioids (Drug Enforcement Administration [DEA], 2016; World Health Organization [WHO], 2016; Baumann et al., 2017; Prekupec et al., 2017).

U-47700 is also actively being used as a legal substitute of illegally abused morphine, heroin, or fentanyl derivatives (Coopman et al., 2016).

It is a potent $\mu$-opioid receptor agonist belonging to the trans1,2-diamine class of analgesics and derived from another opioid analgesic compound, AH-7921 (Coopman et al., 2016; Domanski et al., 2017). 


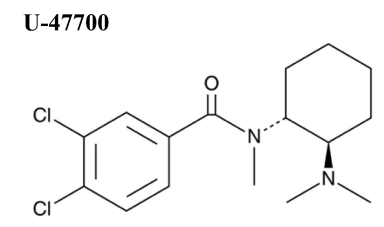

IUPAC NAME: 3,4-Dichloro- $N$-[(1R,2R)-2-(dimethylamino)cyclohexyl]- $N$ methylbenzamide

U-50488

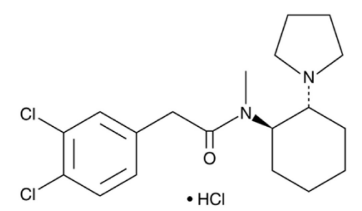

IUPAC NAME: 2-(3,4-dichlorophenyl)-N-methyl-N-[(IR,2R)-2-pyrrolidin-1ylcyclohexyl]acetamide

U-49900

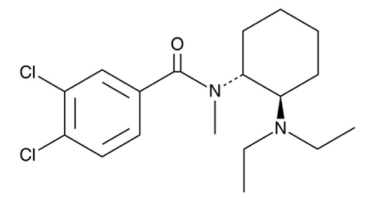

IUPAC NAME: 3,4-dichloro-N-(2-(diethylamino)cyclohexyl)-N-methylbenzamide
U-48800<smiles>CN(C)[C@@H]1CCCC[C@H]1N(C)C(=O)Cc1ccc(Cl)cc1Cl</smiles>

IUPAC NAME: 2,4-Dichloro- $N$-[(1R,2R)-2-(dimethylamino) cyclohexyl]- $N$ methylbenzamide

\section{U-51754}

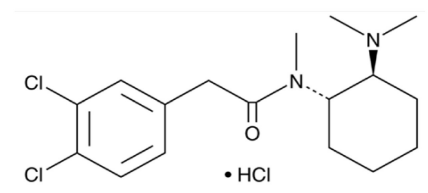

IUPAC NAME:
methylacetamide

AH-7921

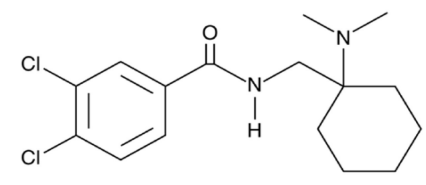

IUPAC NAME: 3,4-dichloro-N-[[1-(dimethylamino)cyclohexyl]methyl]benzamide<smiles>CC(C)=CCN1CCN(C(Cc2cccc(O)c2)c2ccccc2)CC1</smiles>

IUPAC NAME: 1-(3-methyl-2-butenyl)-4-[(1R)-1-phenyl-2-(3hydroxyphenyl)ethyl]piperazine

MT-45<smiles>c1ccc(CC(c2ccccc2)N2CCN(C3CCCCC3)CC2)cc1</smiles>

IUPAC NAME: 1-Cyclohexyl-4-(1,2-diphenylethyl)piperazine
U-47700 was originally developed by the Upjohn Company in 1978 and is about $1 / 10$ as potent as fentanyl and 7.5-fold more potent than morphine in animal models.

Up to now, the compound has never been studied in humans and it is not registered for medical use, but possibly induces typical opioid side effects, including respiratory depression, pinpoint pupils, cyanosis, depressed consciousness, and sedation (World Health Organization [WHO], 2016, 2017; Domanski et al., 2017; Prekupec et al., 2017).

It is likely to be used for its morphine-like pharmacological effects such as varying degrees of sedation, euphoria, a general lift in mood with desired effects being experienced in waves. Consumers also report having experimented a "cool, relaxed" effect (Elliott et al., 2016; Domanski et al., 2017).

The routes of administration, as referred by users in web forums, include the oral, insufflation, intravenous and rectal routes and via an inhaler which contains a liquid solution with a minty taste (World Health Organization [WHO], 2016, 2017). Naive information, always on websites, reports that light doses range from 5 to $7.5 \mathrm{mg}$, common doses from 7.5 to $15 \mathrm{mg}$ and strong doses from 15 to $25 \mathrm{mg}$. Onset of action after oral administration is around $15 \mathrm{~min}$, duration of subjective effects is $5-7 \mathrm{~h}$ and after effects $1-4 \mathrm{~h}$. Similarly, in case of insufflation, onset of action is $15 \mathrm{~min}$, duration of subjective effects is $3-4 \mathrm{~h}$ and hang-over period 1-4 h. Finally in case of intravenous use, onset of action is $0-1 \mathrm{~min}$, duration of subjective effects $1-2 \mathrm{~h}$ and after effects 1-4 h (Zawilska, 2017).
In vitro metabolic profile of $\mathrm{U}-47700$ was recently mapped for the first time using human liver microsomes (HLMs). Found metabolites were in vivo verified by analysis of urine specimens collected after five analytically confirmed cases of overdose from U-47700 consumption.

A total of four metabolites were identified in urine specimens. $N$-Desmethyl-U-47700 was recognized as the principal metabolite of U-47700, while the other detected metabolites were $N, N$-didesmethyl-U-47700, N-Desmethyl-hydroxyl-U-47700, and N,N-Didesmethyl-hydroxyl-U-47700. The study identified also similarities in metabolic transformation between U-47700 and its analog U-49900, resulting in a common metabolite 3,4-dichloro- $N$-(2-aminocyclohexyl)- $N$-methyl-benzamide and isomeric species (Krotulski et al., 2017).

The subjective effects of U-47700 makes it particularly appealing to users when compared to other substances. Indeed, consumers described it as producing more euphoric effects than other fentanyl analogs, more potent in its action than $\mathrm{AH}$ 7921, cheap, and easily available (Fabregat-Safont et al., 2017). Users also report the induction of tolerance and the emergence of withdrawal signs and symptoms upon discontinuing use of this compound, being this occurrence suggestive of physical dependence (World Health Organization [WHO], 2016, 2017).

However, abuse of the drug often happens unknowingly to the user, unaware of what he/she is consuming or in other cases the substance is encountered in combination with other drugs (heroin, fentanyl, and fentanyl analogs). Since substances like 
U-47700 are often produced in illegal laboratories, the identity, purity, and effective dose of the product are unknown (Drug Enforcement Administration [DEA], 2016).

In Belgium a seizure of 'spice-like' incense found out, after toxicological analysis, the presence of U-47700 in the herbal mixture. This finding generated great concern, since users appeared to be not aware that they were consuming such a substance openly sold on the Internet as "legal high" (Coopman and Cordonnier, 2017).

Users abusing U-47700 appear to overlap with the individuals abusing prescription opioid analgesics, 'designer opioids' or heroin, as evidenced by drug use history documented in U-47700 fatal overdose cases (Drug Enforcement Administration [DEA], Department of Justice, 2016).

A number of fatalities and non-fatal intoxications from U47700 have occurred in United States and Europe (Coopman et al., 2016; Elliott et al., 2016; Mohr et al., 2016; Armenian et al., 2017b; Domanski et al., 2017; Ellefsen et al., 2017; Jones et al., 2017; McIntyre et al., 2017; Rao and Nelson, 2017; Rambaran et al., 2017; Schneir et al., 2017; Seither and Reidy, 2017; Shoff et al., 2017), with concentrations varying widely, ranging from 7.6 to $1,460 \mathrm{ng} / \mathrm{mL}$; while in other 16 confirmed fatalities across United States, blood concentrations ranged from 17 to $490 \mathrm{ng} / \mathrm{mL}$ (Mohr et al., 2016; Logan et al., 2017; World Health Organization [WHO], 2017). In 2016, U-47700 was identified for the first time in East and South-East Asia (United Nations Office on Drugs and Crime [UNODC], 2017a).

Reported symptoms of non-fatal intoxication included respiratory depression, agonal breathing, cyanosis, pinpoint pupils, bilateral pulmonary consolidation, atelectasis, anxiety, nausea, abdominal pain, shivering (Elliott et al., 2016; Armenian et al., 2017a; Domanski et al., 2017; Fleming et al., 2017).

Fatal intoxications have been mostly attributed to cardiac arrest, pulmonary and cerebral edema, cardiomegaly and to the depressant effect on the central nervous system, notably causing respiratory depression (Elliott et al., 2016; Fleming et al., 2017).

An additional compound analog of $\mathrm{U}-47700$ recently emerged on the web is U-48800 (3,4-Dichloro- $N$-[(1R,2R)2-(dimethylamino)cyclohexyl]-N-methylbenzamide). Available information is from drug fora (Bluelight, Reddit) or from research chemicals vendors on the web. Indeed, this agent is available as a research chemical of the opioid analgesic class to replace U-47700. U-48800 was also developed by the Upjohn company in the 1970 s and it acts as a selective agonist of the $\mu$-opioid receptor and has around 7.5 -fold the potency of morphine in animal models.

$\mathrm{U}-48800$ became the lead compound of selective kappa-opioid receptor ligands such as U-50488, U-51754 (containing a single methylene spacer difference) and U-69593, which share very similar structures. Although not used medically, the selective kappa ligands are used in research (Research chemical, 2018).

\section{U-49900}

U-49900

(3,4-dichloro- $N$-(2-(diethylamino) cyclohexyl)- $N$ methylbenzamide) is a structural analog of U-47700 with sparse clinical data available. The structural similarities with U-47700 raises concern regarding the risks associated with U-49900 use. Currently, no reported deaths have been associated with $\mathrm{U}-49900$, but this agent is growing in popularity as a replacement or an alternative to the scheduled U-47700. Worldwide use is increasing as it has been specifically documented in some European countries such as Sweden and Spain (Alzghari et al., 2017).

Although both substance names are very similar, U-49900 does not pertain to the same Upjohn patent as the one already mentioned for U-47700 or U-51754, and it is in fact a completely new synthetic opioid (Fabregat-Safont et al., 2017).

Similarly to what happened with U-47700, Krotulski et al. (2017) mapped for the first time the generation of in vitro metabolic profile of U-49900 using HLMs. Metabolites were confirmed in vivo by analysis of human urine specimens collected after one case report of overdose following U-49900 ingestion. In urine specimens, five metabolites of U-49900 were overall identified. $N$-Desethyl-U-49900 was established to be the main metabolite of U-49900 following microsomal incubations, while $N, N$-didesethyl-N-desmethyl-U-49900 was the most abundant in another urine specimen: the other identified metabolites were N,N-Didesethyl-U-49900, N-Desethyl-hydroxyl-U-49900 and $N$-Desethyl- $N$-desmethyl-U-49900.

As previously mentioned, U-47700 and U-49900 metabolize to a common metabolite 3,4-dichloro- $N$-(2-aminocyclohexyl)- $N$ methyl-benzamide, and this is an important information for the analysts, especially in case of increasing prevalence of U-49900 in the street drug scenario (Krotulski et al., 2017).

U-49900 firstly appeared online in 2016 on a popular drug forum $^{1}$ by a drug user reporting its availability and asking other users about possible dangerous effects. Since the substance is a close analog to U-47700, users expressed concerns about its potential health risks, such as harms caused by nasal and rectal passages, damaged veins, severe withdrawals, and other serious side effects such as loss of taste, smell and of the sense of touch, pain upon insufflation, neurologic pain on the left side of the body and a foam-like discharge from the lungs. In a Swedish forum, a consumer reported usual opioid effects when using a U-49900 dose of $50 \mathrm{mg}$ of the drug intravenously, while at lower doses of 5-10 mg other users informed on no effects. Conversely, in those latter amounts $(5-10 \mathrm{mg}) \mathrm{U}-47700$ is already active. Hence, U49900 needs to be probably consumed at higher doses to have significant effects (Fabregat-Safont et al., 2017).

\section{$\mathrm{AH}-7921$}

AH-7921 (3,4-dichloro- $N$ - $\{[1$-(dimethylamino)-cyclohexyl $]$ methyl\}benzamide) is an opioid structurally similar to U-47700 and firstly developed by Allen and Hanburys in the mid-1970s, with extensive in vitro and in animal studies, but it has never made available for medical use, because of its heavy addictive properties. AH-7921 was firstly identified in 2012 in samples of a product known as Doxylam which was used by Internet retailers as an alternative name for $\mathrm{AH}-7921$. The name Doxylam could be easily confounded with the name of an antihistamine drug with sedative-hypnotic properties, doxylamine, present in several over-the-counter medicines. The accidental use of

$\overline{{ }^{1} \text { http://www.bluelight.org/vb/forum.php? }}$ 
AH-7921/doxylam for the treatment of allergy or as a hypnotic might lead to serious health damages (Zawilska, 2017). There is therefore a concern that individuals looking for obtaining the unrelated hypnotic 'Doxylamine' might accidentally purchase AH-7921, mislabeled as 'Doxylam, which could lead to unintentional drug overdoses (European Monitoring Centre for Drugs, and Drug Addiction [EMCDDA], 2014).

AH-7921 recently entered the illicit drug market as new psychotropic substance in countries such as Japan, United States and Europe, resulting in several fatalities and intoxications (Karinen et al., 2014; Kronstrand et al., 2014; Coppola and Mondola, 2015; Coopman et al., 2016; Armenian et al., 2017b; Dolengevich-Segal et al., 2017; Domanski et al., 2017; Fels et al., 2017). In fatalities occurred in European countries, the reported blood concentrations ranged from 31 to $1,449 \mathrm{ng} / \mathrm{mL}$ (Logan et al., 2017).

AH-7921 is an agonist of $\mu$ and $\kappa$ opioid receptors, with a moderate selectivity toward $\mu$ opioid receptors, a narrow therapeutic window, and may cause dependence (Zawilska and Andrzejczak, 2015). It is 1.7 -fold more potent than morphine at inducing respiratory depression in mice, suggesting greater risk for adverse effects in humans (Prekupec et al., 2017; Tracy et al., 2017).

AH-7921 can be purchased on the web market under the guise of being a research chemical 'not for human consumption' and it has also been detected in synthetic cannabinoid products (Karinen et al., 2014; Fabregat-Safont et al., 2017). Wohlfarth et al. (2016) comprehensively studied AH-7921 metabolism, by assessing HLM metabolic stability and determining AH-7921 metabolic profile after human hepatocytes incubation. Then, the findings in a urine case specimen were confirmed and results were compared to in silico predictions. Twelve AH-7921 metabolites after hepatocyte incubation were identified, mainly generated by demethylation, less dominantly by hydroxylation, and combinations of different biotransformations. The two major metabolites after hepatocyte incubation, also identified in the urine case specimen, were desmethyl and di-desmethyl AH-7921. Together with the glucuronidated metabolites, these are likely suitable analytical targets for documenting AH-7921 intake (Wohlfarth et al., 2016).

Users describe its effects to be similar to the classical opioids' ones including euphoria, mental relaxation, pleasant mood lift; while the side effects include sedation, miosis, nausea, vertigo, hypertension, tachycardia, respiratory depression, hypothermia, and withdrawal symptoms possibly worse than morphine due to its much longer half-life (Coppola and Mondola, 2015; Katselou et al., 2015; Fabregat-Safont et al., 2017).

The substance is sold in the form of capsules, tablets or powder and administration routes described in the web forums include mainly the oral, but also inhaled (vaporized), intravenous, intranasal, sublingual and intrarectal routes with a high risk of overdose (Coppola and Mondola, 2015; Katselou et al., 2015; Dolengevich-Segal et al., 2017). Light doses are from 5 to $10 \mathrm{mg}$, common doses from 10 to 25 and strong doses $>25 \mathrm{mg}$. Onset of action for oral administration is $15-45 \mathrm{~min}$, duration $6-8 \mathrm{~h}$ and after effects 1-6 h (Zawilska, 2017).
In 2013, AH-7921 was detected in several cases of acute non-fatal intoxications and deaths in United States and European countries such as in Sweden, United Kingdom and Norway, combined with other substances such as cannabis, alcohol, synthetic cathinones, benzodiazepines, metoxetamine, or gabapentin. Lung edema was evidenced during the autopsy in most of the dead people (Coppola and Mondola, 2015; Katselou et al., 2015; Dolengevich-Segal et al., 2017).

In all the reported fatalities, cause of death could be attributed to respiratory depression. In a specific case, the autopsy revealed cerebral edema with moderate to increased intracranial pressure. Moreover, signs for an incipient pneumonia in the central lung sections were found (Fels et al., 2017). The absence of pharmacokinetic and pharmacodynamic information in humans makes the risk related to AH-7921 consumption combined with other central nervous system depressants unknown. Currently available information confirms that AH-7921 is a potent respiratory depressant with a high addictive potential (Coppola and Mondola, 2015).

\section{NSOs of Acetamide Family U-50488, U-51754}

Information about U-50488 and U-51754 is quite scant. These acetamides are U-47700 related compounds, being part of the trans-1,2-diamine opioid analgesic chemical class synthesized by the Upjohn Company in the attempt to produce a non-addicting analgesic as potent as morphine (Mohr et al., 2016; Amin et al., 2017; Domanski et al., 2017; Fleming et al., 2017).

U-50488 (2-(3,4-dichlorophenyl)- $N$-methyl- $N$-[(1R,2R)2-pyrrolidin-1-ylcyclohexyl]acetamide) is a $\kappa$-opioid receptor agonist (KOR) with analgesic properties and some reported $\mu$-opioid receptor respiratory antagonist effects (Mohr et al., 2016; Baumann et al., 2017; Domanski et al., 2017).

In animal models, U-50488 has been studied for its diuretic, antitussive, analgesic and anticonvulsant properties, but it is known to induce dysphoria and stress-like effects in rodents (Muschamp et al., 2012; Mohr et al., 2016; Amin et al., 2017). U-50488 abuse potential is unknown and at present this synthetic opioid is an uncontrolled substance available online from companies selling research chemicals (Mohr et al., 2016). Currently, information about the toxicological profile and toxicoepidemiology of U-50488 is poor, although the structural similarity of U-50488 to U-47700 poses users at potential health risks associated with its abuse and easy accessibility (Amin et al., 2017).

U-51754 (trans-3,4-dichloro- $N$-[2-(dimethylamino)cyclo hexyl]- $N$-methyl-benzeneacetamide) derived from the same Upjohn patent, has also recently appeared on the market. This substance is not as selective for KOR, and with respect to the effects, consumers report that it is more dysphoric and dissociating than U-47700 (Fabregat-Safont et al., 2017).

\section{NSOs of Piperazine Family MT-45}

MT-45 (1-cyclohexyl-4-(1,2-diphenylethyl)piperazine) is a piperazine derivative chemically unrelated to other opioid 
agonists, originally synthesized in the 1970s in a Japanese laboratory as an analgesic agent. It is an agonist of $\kappa, \mu$ and $\delta$ opioid receptors, with analgesic and sedative effects, with a potency nearly identical to morphine and highly addictive potential, although it has not been studied in human (Lindeman et al., 2014; Papsun et al., 2016; Baumann et al., 2017; Dolengevich-Segal et al., 2017; Logan et al., 2017). In animal studies MT-45 showed a high toxicity (Montesano et al., 2017).

MT-45 has been associated with a number of deaths in United States and Europe (especially in Sweden) (Bradley et al., 2016; Papsun et al., 2016; Baumann et al., 2017; Fels et al., 2017; Logan et al., 2017; Montesano et al., 2017). In 2016, MT-45 was identified for the first time in East and South-East Asia (United Nations Office on Drugs and Crime [UNODC], 2017a).

The light doses orally used range from 30 to $45 \mathrm{mg}$, the common from 45 to $60 \mathrm{mg}$ and the strong $>60 \mathrm{mg}$. Onset of action is $30-45 \mathrm{~min}$, duration is $4-6 \mathrm{~h}$ and after effects $2-3 \mathrm{~h}$ (Zawilska, 2017).

MT-45 blood concentrations in the reported deaths ranged from 8.3 to $1,989 \mathrm{ng} / \mathrm{mL}$; while in a few non-fatal intoxications MT-45 was detected in blood at 6-157 ng/mL (Logan et al., 2017).

A recent study by Montesano et al. (2017), identified the chemical structures of 14 Phase I and II MT-45 metabolites, using primarily the prediction in silico, then the metabolites were confirmed by in vivo experiments. The detected metabolites are principally products of mono- or dihydroxylation, and $\mathrm{N}$-dealkylation; in addition it was observed also a glucuronide conjugation of mono- and dihydroxylated metabolites. Hydroxylated MT-45 showed to be bioactive and may contribute to the overall pharmacotoxicological profile of MT-45 in vivo. The knowledge of Phases I and II MT-45 metabolite structure is necessary to develop analytical methods to detect MT45 for clinical and forensic purposes (Montesano et al., 2017).

MT-45 surfaced on internet shops late 2012 (Fabregat-Safont et al., 2017) and was first reported as a new psychoactive substance (NPS) through the Early Warning System of the EMCDDA in December 2013 (Armenian et al., 2017b). Internet suppliers and retailers typically sell MT-45 in its dihydrochloride salt form. It has been seized mixed with other drugs, including synthetic cannabinoids or in combination with synthetic cathinones ("Wow") (Schifano et al., 2015; Papsun et al., 2016).

Users report a slow onset of action, which possibly increases the risk of toxic overdose from redosing before peak effect is reached. Intravenous administration of MT-45 is 11 times more lethal than morphine according to data observed in mice (Helander et al., 2014; Prekupec et al., 2017). MT-45 and novel fentanyls are probably similar in addictive potential and withdrawal effects (Tracy et al., 2017).

Clinical data from 12 analytically confirmed hospital cases of MT-45 poisoning, demonstrate that, similarly to other opioids, the main dangerous effects of MT-45, are respiratory depression, cognitive deficits, and loss of consciousness. A few users reported bilateral hearing loss and significant auditory symptoms with transient tinnitus, whilst a pronounced sensorineural hearing loss still present at 2 weeks follow-up affected one user. Hence MT-45 may be an ototoxic substance (Helander et al., 2014; Lindeman et al., 2014; Papsun et al., 2016; Dolengevich-Segal et al., 2017).

Other side effects, unclearly attributable solely on MT-45 or another contaminant, include folliculitis and dermatitis with hair loss, dry eyes, elevated liver enzymes, leukonychia striata (Mees' lines), typically found in thallium poisoning, and severe bilateral cataracts requiring surgery (Armenian et al., 2017b; Helander et al., 2017b). In a case report, autopsy revealed brain and hemorrhagic pulmonary edema and hyperemia of the internal organs (Fels et al., 2017).

Administration routes of MT-45 are typically oral or by nasal aspiration, but also intravenous, sublingual, intrarectal, or inhaled (vaporized). Typical doses reported by users are 15-30 mg for insufflation and 25-75 mg for oral administration; desired effects can last for up to $2 \mathrm{~h}$ (Zawilska and Andrzejczak, 2015). The effects sought by users is a sensation of well-being, relaxation and euphoria. In Switzerland 30 fatalities and several acute intoxications have been recently reported (DolengevichSegal et al., 2017).

Another piperazine, AD-1211 (1-(3-methyl-2-butenyl)-4[(1R)-1-phenyl-2-(3-hydroxyphenyl)ethyl]piperazine), was also synthesized in the 1970s by the same Japanese laboratory which created MT-45. This compound has narcotic and analgesic antagonist activities with a physical dependence weaker than that of pentazocine (an opioid painkiller) (Natsuka et al., 1987). Information on this compound is limited and no pharmacotoxicological properties have been reported in the international literature.

\section{CONCLUSION}

Novel synthetic opioids were originally synthesized by pharmaceutical companies in their research for analgesic drugs without addictive properties. However, because of their toxicity or abuse potential, the NSOs reported in this review were never approved for medical use. Currently NSOs are mainly used by individuals who already used heroin, prescription opioids, or other illicit opioids looking for same opiates effects: relaxation, sedation, and euphoria. Psychonauts (from the Ancient Greek

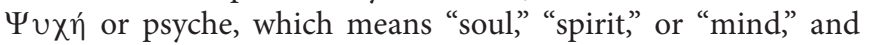

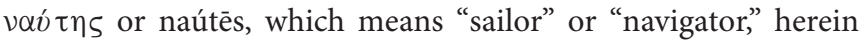
indicating a modern drug users seeking for altered mental states) appear also interested in experimenting the eventual peculiar effects of these NPSs.

Novel synthetic opioids are readily available on internet web sites and often used in association with other recreational drugs, leading to a public health danger in many countries worldwide. These substances have been causing severe intoxications and deaths pushing the United States and European governments to take the necessary measures to prevent their further spread.

Unfortunately, conventional drug tests do not currently detect the NSOs reported in this review. The growing number of acute intoxication cases, often associated with polyabuse, indicates that pharmacological, toxicological, and forensic research on these compounds is highly needed in order to determine 
their pharmacokinetic profiles, long-term effects, and effective detection methods.

\section{AUTHOR CONTRIBUTIONS}

All the authors searched for bibliographic material, drafted different chapter of the manuscript, and contributed

\section{REFERENCES}

Alzghari, S. K., Amin, Z. M., Chau, S., Fleming, S. W., Cho, K., and Fung, V. (2017). On the horizon: the synthetic opioid U-49900. Cureus 9:e1679. doi: $10.7759 /$ cureus. 1679

Amin, Z. M., Rambaran, K. A., Fleming, S. W., Cho, K., Chacko, L., and Alzghari, S. K. (2017). Addressing hazards from unscheduled novel psychoactive substances as research chemicals: the case of U-50488. Cureus 9:e1914. doi: 10.7759/cureus.1914

Armenian, P., Olson, A., Anaya, A., Kurtz, A., Ruegner, R., and Gerona, R. R. (2017a). Fentanyl and a novel synthetic opioid U-47700 masquerading as Street "Norco" in Central California: a case report. Ann. Emerg. Med. 69, 87-90. doi: 10.1016/j.annemergmed.2016.06.014

Armenian, P., Vo, K. T., Barr-Walker, J., and Lynch, K. L. (2017b). Fentanyl, fentanyl analogs and novel synthetic opioids: a comprehensive review. Neuropharmacology 134, 121-132. doi: 10.1016/j.neuropharm.2017.10.016

Bäckberg, M., Beck, O., Jönsson, K. H., and Helander, A. (2015). Opioid intoxications involving butyrylfentanyl, 4-fluorobutyrylfentanyl, and fentanyl from the Swedish STRIDA project. Clin. Toxicol. 53, 609-617. doi: 10.3109/ 15563650.2015.1054505

Baumann, M. H., Majumdar, S., Le Rouzic, V., Hunkele, A., Uprety, R., Huang, X. P., et al. (2017). Pharmacological characterization of novel synthetic opioids (NSO) found in the recreational drug marketplace. Neuropharmacology 134, 101-107. doi: 10.1016/j.neuropharm.2017.08.016

Bradley, M., Hasselblad, A., Norlen, L., Lapins, J., Bäckberg, M., and Helander, A. (2016). Acute cutaneous symptom complex with subsequent cataract. The internet drug MT-45 may be the cause. Lakartidningen 113:DTAF.

Carroll, F. I., Lewin, A. H., Mascarella, S. W., Seltzman, H. H., and Reddy, P. A. (2012). Designer drugs: a medicinal chemistry perspective. Ann. N. Y. Acad. Sci. 1248, 18-38. doi: 10.1111/j.1749-6632.2011.06199.x

Cittern, P. A., Kapoor, V. K., and Parfitt, R. T. (1986). Preparation and analgesic activity of (-)-11 alpha-substituted 1,2,3,4,5,6-hexahydro-6 alpha,7(methyleneoxy)-2,6-methano-3-benzazocines. J. Med. Chem. 29, 1929-1933. doi: $10.1021 / \mathrm{jm} 00160 \mathrm{a} 022$

Coopman, V., Blanckaert, P., Van Parys, G., Van Calenbergh, S., and Cordonnier, J. (2016). A case of acute intoxication due to combined use of fentanyl and 3,4-dichloro-N-[2-(dimethylamino)cyclohexyl]-N-methylbenzamide (U47700). Forensic Sci. Int. 266, 68-72. doi: 10.1016/j.forsciint.2016.05.001

Coopman, V., and Cordonnier, J. (2017). Spice-like herbal incense laced with the synthetic opioid U-47700. Toxicol. Anal. Clin. 30, 75-79.

Coppola, M., and Mondola, R. (2015). AH-7921: a new synthetic opioid of abuse. Drug Alcohol Rev. 34, 109-110. doi: 10.1111/dar.12216

Dolengevich-Segal, H., Rodríguez-Salgado, B., Gómez-Arnau, J., and SánchezMateos, D. (2017). An approach to the new psychoactive drugs phenomenon. Salud Ment. 40, 71-82. doi: 10.17711/SM.0185-3325.2017.010

Domanski, K., Kleinschmidt, K. C., Schulte, J. M., Fleming, S., Frazee, C., Menendez, A., et al. (2017). Two cases of intoxication with new synthetic opioid, U-47700. Clin. Toxicol. 55, 46-50. doi: 10.1080/15563650.2016.120 9763

Drug Enforcement Administration (DEA), Department of Justice (2016). Schedules of controlled substances: temporary placement of U-47700 into schedule I. Final Order 81, 79389-79393.

Drug Enforcement Administration [DEA] (2016). DEA Schedules Deadly Synthetic Drug U-47700. DEA News. Available at: https://www.dea.gov/divisions/hq/ 2016/hq111016.shtml

Dwyer, J. B., Janssen, J., Luckasevic, T. M., and Williams, K. E. (2017). Report of increasing overdose deaths that include acetyl fentanyl in multiple counties of substantially to manuscript intellectual content and revision.

\section{FUNDING}

The work was supported by Presidency of the Ministers Council, Department of Antidrug Policy.

the Southwestern Region of the Commonwealth of Pennsylvania in 2015-2016. J. Forensic Sci. 63, 195-200. doi: 10.1111/1556-4029.13517

Elbaridi, N., Kaye, A. D., Choi, S., and Urman, R. D. (2017). Current concepts of phenylpiperidine derivatives use in the treatment of acute and chronic pain. Pain Phys. 20, SE23-SE31.

Ellefsen, K. N., Taylor, E. A., Simmons, P., Willoughby, V., and Hall, B. J. (2017). Multiple Drug-toxicity involving novel psychoactive substances, 3fluorophenmetrazine and U-47700. J. Anal. Toxicol. 41, 765-770. doi: 10.1093/ jat/bkx060

Elliott, S. P., Brandt, S. D., and Smith, C. (2016). The first reported fatality associated with the synthetic opioid 3,4-dichloro-N-[2-(dimethyl amino)cyclohexyl]-N-methylbenzamide (U-47700) and implications for forensic analysis. Drug Test Anal. 8, 875-879. doi: 10.1002/dta.1984

European Monitoring Centre for Drugs, and Drug Addiction [EMCDDA] (2014). AH-. (7921). Report on the Risk Assessment of 3,4-dichloro-N-\{[1-(dimethyl amino)Cyclohexyl]methyl\}benzamide (AH-7921) in the Framework of the Council Decision on New Psychoactive Substances. Luxembourg: Publications Office of the European Union.

European Monitoring Centre for Drugs, and Drug Addiction [EMCDDA] (2016). The Internet and Drug Markets. Luxembourg: Publications Office of the European Union.

European Monitoring Centre for Drugs, and Drug Addiction [EMCDDA] (2017). High Risk Drug use and New Psychoactive Substances. EMCDDA Rapid Communication. Luxembourg: Publications Office of the European Union.

Fabregat-Safont, D., Carbón, X., Ventura, M., Fornís, I., Guillamón, E., Sancho, J. V., et al. (2017). Updating the list of known opioids through identification and characterization of the new opioid derivative 3,4-dichloro-N(2-(diethylamino)cyclohexyl)-N-methylbenzamide (U-49900). Sci. Rep. 7:6338. doi: 10.1038/s41598-017-06778-9

Fels, H., Krueger, J., Sachs, H., Musshoff, F., Graw, M., Roider, G., et al. (2017). Two fatalities associated with synthetic opioids: AH-7921 and MT-45. Forensic Sci. Int. 277, e30-e35. doi: 10.1016/j.forsciint.2017.04.003

Fleming, S. W., Cooley, J. C., Johnson, L., Frazee, C. C., Domanski, K., Kleinschmidt, K., et al. (2017). Analysis of U-47700, a novel synthetic opioid, in human urine by LC-MS-MS and LC-QToF. J. Anal. Toxicol. 41, 173-180. doi: 10.1093/jat/bkw131

Giorgetti, A., Centola, C., and Giorgetti, R. (2017). Fentanyl novel derivativerelated deaths. Hum. Psychopharmacol. 32:3. doi: 10.1002/hup.2605

Guerrieri, D., Rapp, E., Roman, M., Druid, H., and Kronstrand, R. (2017). Postmortem and toxicological findings in a series of furanylfentanylrelated deaths. J. Anal. Toxicol. 41, 242-249. doi: 10.1093/jat/ bkw129

Guerrini, K., Argo, A., Borroni, C., Catalano, D., Dell'acqua, L., Faré, F., et al. (2013). Development and validation of a reliable method for studying the distribution pattern for opiates metabolites in brain. J. Pharm. Biomed. Anal. 73, 125-130. doi: 10.1016/j.jpba.2012.04.001

Helander, A., Bäckberg, M., and Beck, O. (2014). MT-45, a new psychoactive substance associated with hearing loss and unconsciousness. Clin. Toxicol. 52, 901-904. doi: 10.3109/15563650.2014.943908

Helander, A., Bäckberg, M., Signell, P., and Beck, O. (2017a). Intoxications involving acrylfentanyl and other novel designer fentanyls - results from the Swedish STRIDA project. Clin. Toxicol. 55, 589-599. doi: 10.1080/15563650. 2017.1303141

Helander, A., Bradley, M., Hasselblad, A., Norlén, L., Vassilaki, I., Bäckberg, M., et al. (2017b). Acute skin and hair symptoms followed by severe, delayed eye complications in subjects using the synthetic opioid MT-45. Br. J. Dermatol. 176, 1021-1027. doi: 10.1111/bjd.15174 
Hill, S. L., and Thomas, S. H. L. (2016). Drugs of abuse. Medicine 44, 160-169. doi: 10.1016/j.mpmed.2015.12.030

Jones, M. J., Hernandez, B. S., Janis, G. C., and Stellpflug, S. J. (2017). A case of U-47700 overdose with laboratory confirmation and metabolite identification. Clin. Toxicol. 55, 55-59. doi: 10.1080/15563650.2016.1209767

Karinen, R., Tuv, S. S., Rogde, S., Peres, M. D., Johansen, U., Frost, J., et al. (2014). Lethal poisonings with AH-7921 in combination with other substances. Forensic Sci. Int. 244, e21-e24. doi: 10.1016/j.forsciint.2014.08.013

Katselou, M., Papoutsis, I., Nikolaou, P., Spiliopoulou, C., and Athanaselis, S. (2015). AH-7921: the list of new psychoactive opioids is expanded. Forensic Toxicol. 33, 195-201. doi: 10.1007/s11419-015-0271-z

Knapp, C. M. (2002). Opiates. Encycl. Hum. Brain 3, 729-739. doi: 10.1016/B0-12227210-2/00260-0

Kronstrand, R., Thelander, G., Lindstedt, D., Roman, M., and Kugelberg, F. C. (2014). Fatal intoxications associated with the designer opioid AH-7921. J. Anal. Toxicol. 38, 599-604. doi: 10.1093/jat/bku057

Krotulski, A. J., Mohr, A. L. A., Papsun, D. M., and Logan, B. K. (2017). Metabolism of novel opioid agonists U-47700 and U-49900 using human liver microsomes with confirmation in authentic urine specimens from drug users. Drug Test Anal. 10, 127-136. doi: 10.1002/dta.2228

Lindeman, E., Bäckberg, M., Personne, M., and Helander, A. (2014). MT-45-a dangerous and potentially ototoxic internet drug. Lakartidningen 111, 17121715 .

Logan, B. K., Mohr, A. L. A., Friscia, M., Krotulski, A., Papsun, D. M., Kacinko, S. L., et al. (2017). Reports of adverse events associated with use of novel psychoactive substances, 2013-2016: a review. J. Anal. Toxicol. 41, 573-610. doi: $10.1093 /$ jat/bkx031

Lucyk, S. N., and Nelson, L. S. (2017). Novel synthetic opioids: an opioid epidemic within an opioid epidemic. Ann. Emerg. Med. 69, 91-93. doi: 10.1016/j. annemergmed.2016.08.445

Marchei, E., Pacifici, R., Mannocchi, G., Marinelli, E., Busardò, F. P., and Pichini, S. (2018). New synthetic opioids in biological and non-biological matrices: a review of current analytical methods. Trends Analyt. Chem. 102, 1-15. doi: 10.1016/j.trac.2018.01.007

McIntyre, I. M., Gary, R. D., Joseph, S., and Stabley, R. (2017). A fatality related to the synthetic opioid U-47700: postmortem concentration distribution. J. Anal. Toxicol. 41, 158-160. doi: 10.1093/jat/bkw124

Mohr, A. L., Friscia, M., Papsun, D., Kacinko, S. L., Buzby, D., and Logan, B. K. (2016). Analysis of novel synthetic opioids U-47700, U-50488 and Furanyl fentanyl by LC-MS/MS in postmortem casework. J. Anal. Toxicol. 40, 709-717. doi: $10.1093 /$ jat/bkw086

Montesano, C., Vannutelli, G., Fanti, F., Vincenti, F., Gregori, A., Rita Togna, A., et al. (2017). Identification of MT-45 Metabolites: in silico prediction, In Vitro incubation with rat hepatocytes and In Vivo confirmation. J. Anal. Toxicol. 41, 688-697. doi: 10.1093/jat/bkx058

Mounteney, J., Giraudon, I., Denissov, G., and Griffiths, P. (2015). Fentanyls: are we missing the signs? Highly potent and on the rise in Europe. Int. J. Drug Policy 26, 626-631. doi: 10.1016/j.drugpo.2015.04.003

Muschamp, J. W., Nemeth, C. L., Robison, A. J., Nestler, E. J., and Carlezon, W. A. Jr. (2012). $\triangle$ FosB enhances the rewarding effects of cocaine while reducing the pro-depressive effects of the kappa-opioid receptor agonist U50488. Biol. Psychiatry 71, 44-50. doi: 10.1016/j.biopsych.2011.08.011

Natsuka, K., Nakamura, H., Nishikawa, Y., Negoro, T., Uno, H., and Nishimura, H. (1987). Synthesis and structure-activity relationships of 1 -substituted $4-(1,2-$ diphenylethyl)piperazine derivatives having narcotic agonist and antagonist activity. J. Med. Chem. 30, 1779-1787. doi: 10.1021/jm00393a017

Papsun, D., Krywanczyk, A., Vose, J. C., Bundock, E. A., and Logan, B. K. (2016). Analysis of MT-45, a novel synthetic opioid, in human whole blood by LC-MSMS and its identification in a drug-related death. J. Anal. Toxicol. 40, 313-317. doi: 10.1093/jat/bkw012

Pichini, S., Pacifici, R., Marinelli, E., and Busardò, F. P. (2017a). European drug users at risk from illicit fentanyls mix. Front. Pharmacol. 8:785. doi: 10.3389/ fphar.2017.00785

Pichini, S., Solimini, R., Berretta, P., Pacifici, R., and Busardò, F. P. (2017b). Acute intoxications and fatalities from illicit fentanyl and analogues: an update. Ther. Drug Monit. 40, 38-51. doi: 10.1097/FTD.0000000000000465

Prekupec, M. P., Mansky, P. A., and Baumann, M. H. (2017). Misuse of novel synthetic opioids: a deadly new trend. J. Addict Med. 11, 256-265. doi: 10.1097/ ADM.0000000000000324
Raffa, R. B., Pergolizzi, J. V. Jr., LeQuang, J. A., Taylor, R. Jr., Nema Research Group, and Colucci, S. (2018). The fentanyl family: a distinguished medical history tainted by abuse. J. Clin. Pharm. Ther. 43, 154-158. doi: 10.1111/jcpt.12640

Rambaran, K. A., Fleming, S. W., An, J., Burkhart, S., Furmaga, J., Kleinschmidt, K. C., et al. (2017). U-47700: a clinical review of the literature. J. Emerg. Med. 53, 509-519. doi: 10.1016/j.jemermed.2017.05.034

Rao, R. B., and Nelson, L. S. (2017). The new opioid epidemic: prescriptions, synthetics, and street drugs. Emerg. Med. 49, 65-70. doi: 10.12788/emed.2017. 0010

Research chemical (2018). Legal Strong U 48800 MAF White Powder C16H22Cl2N2O For Medical Research. Available at: http://www. researchchemical-intermediates.com/sale-10213783-legal-strong-u-48800maf-white-powder-c16h22cl2n2o-for-medical-research.html

Schifano, F., Orsolini, L., Duccio Papanti, G., and Corkery, J. M. (2015). Novel psychoactive substances of interest for psychiatry. World Psychiatry 14, 15-26. doi: 10.1002/wps.20174

Schneir, A., Metushi, I. G., Sloane, C., Benaron, D. J., and Fitzgerald, R. L. (2017). Near death from a novel synthetic opioid labeled U-47700: emergence of a new opioid class. Clin. Toxicol. 55, 51-54. doi: 10.1080/15563650.2016.1209764

Seither, J., and Reidy, L. (2017). Confirmation of Carfentanil, U-47700 and other synthetic opioids in a human performance case by LC-MS-MS. J. Anal. Toxicol. 41, 493-497. doi: 10.1093/jat/bkx049

Shoff, E. N., Zaney, M. E., Kahl, J. H., Hime, G. W., and Boland, D. M. (2017) Qualitative Identification of fentanyl analogs and other opioids in postmortem cases by UHPLC-Ion Trap-MSn. J. Anal. Toxicol. 41, 484-492. doi: 10.1093/jat/ bkx041

Suzuki, J., and El-Haddad, S. (2017). A review: fentanyl and non-pharmaceutical fentanyls. Drug Alcohol Depend. 171, 107-116. doi: 10.1016/j.drugalcdep.2016. 11.033

Tracy, D. K., Wood, D. M., and Baumeister, D. (2017). Novel psychoactive substances: types, mechanisms of action, and effects. BMJ 356:i6848. doi: 10. 1136/bmj.i6848

United Nations Office on Drugs and Crime [UNODC] (2017a). The Challenge of Synthetic Drugs in East and South-East Asia. Trends and Patterns of Amphetamine-type Stimulants and New Psychoactive Substances. Report from the Global SMART Programme. Vienna: United Nations Office on Drugs and Crime.

United Nations Office on Drugs and Crime [UNODC] (2017b). World Drug Report 2017. Booklet 4. Vienna: United Nations Publication.

Van Hout, M. C., and Hearne, E. (2017). New psychoactive substances (NPS) on cryptomarket fora: an exploratory study of characteristics of forum activity between NPS buyers and vendors. Int. J. Drug Policy 40, 102-110. doi: 10.1016/ j.drugpo.2016.11.007

Wohlfarth, A., Scheidweiler, K. B., Pang, S., Zhu, M., Castaneto, M., Kronstrand, R., et al. (2016). Metabolic characterization of AH-7921, a synthetic opioid designer drug: in vitro metabolic stability assessment and metabolite identification, evaluation of in silico prediction, and in vivo confirmation. Drug Test Anal. 8, 779-791. doi: 10.1002/dta.1856

World Health Organization [WHO] (2016). U-47700 Critical Review Report. Geneva: WHO.

World Health Organization [WHO] (2017). WHO Expert Committee on Drug Dependence. Thirty-eight Report. Geneva: WHO Press.

Zawilska, J. B. (2017). An expanding world of novel psychoactive substances: opioids. Front. Psychiatry 8:110. doi: 10.3389/fpsyt.2017.00110

Zawilska, J. B., and Andrzejczak, D. (2015). Next generation of novel psychoactive substances on the horizon - A complex problem to face. Drug Alcohol Depend. 157, 1-17. doi: 10.1016/j.drugalcdep.2015.09.030

Conflict of Interest Statement: The authors declare that the research was conducted in the absence of any commercial or financial relationships that could be construed as a potential conflict of interest.

Copyright (C) 2018 Solimini, Pichini, Pacifici, Busardò and Giorgetti. This is an openaccess article distributed under the terms of the Creative Commons Attribution License (CC BY). The use, distribution or reproduction in other forums is permitted, provided the original author(s) and the copyright owner are credited and that the original publication in this journal is cited, in accordance with accepted academic practice. No use, distribution or reproduction is permitted which does not comply with these terms. 